حقيبة برمجية لاختبار العلاقة بين الضغط الوظيفي و الرضام مقترح)

خنساء حكمت سليمان مدرس مساعد-قسم نظم المعلومات داود

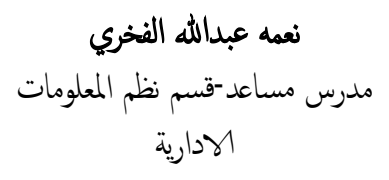

كلية الادارة والاقتصاد-جامعة الموصل

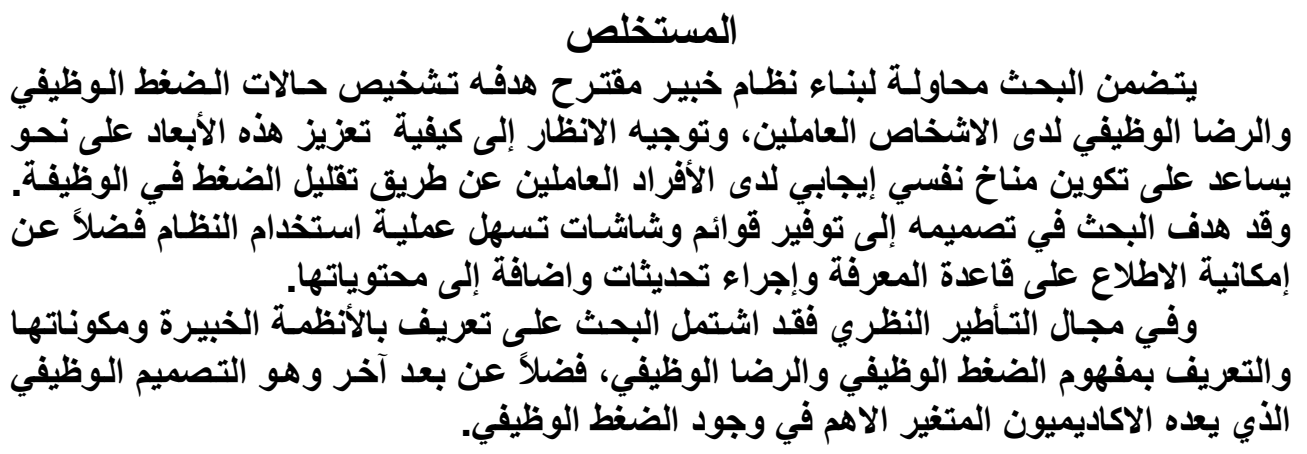

\title{
A Programming Portfolio to Select the Relation between Employment Pressure and Satisfaction \\ (A proposed System)
}

\author{
Ne'ma A. Al-Fackry \\ Assistant Lecturer \\ Management Information \\ Systems \\ University of Mosul
}

\author{
Suhair A. Dawood \\ Assistant Lecturer \\ Management Information \\ Systems \\ University of Mosul
}

\author{
Khansaa H. Sulaiman \\ Assistant programmer \\ Computers Unit \\ University of Mosul
}

\section{Abstract}

The research includes an attempt to build a proposed experience system which aims to diagnose the cases of the functional pressure and the functional satisfaction for the employees and to direct the eyesight to how to do in supporting these directions for

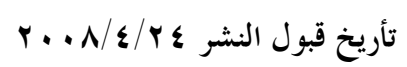

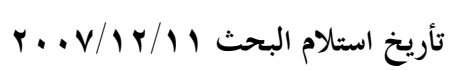


establishing a positive psychological environment to the employs. This can be done by decreasing the pressure in the work. The system design aims to provide lists and forms that facilitate the use of the system. In addition to that, the ability of displaying the knowledge base with the activities of adding and updating of its contents. In the theoretical part, the research included a definition of the experience systems and their contents, a definition of the concepts of functional pressure, functional satisfaction, and the functional design which is the important variable in existence of the functional pressure.

المقدمة

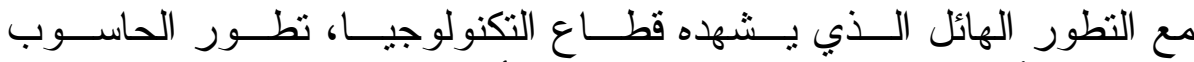

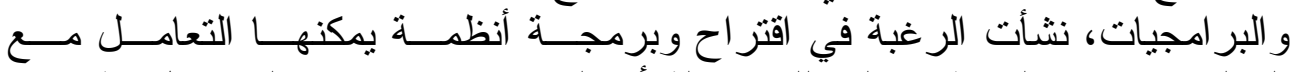

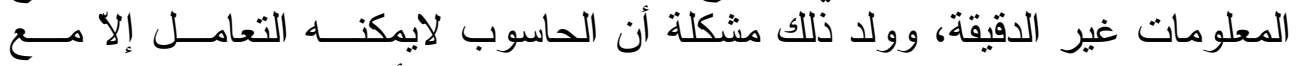

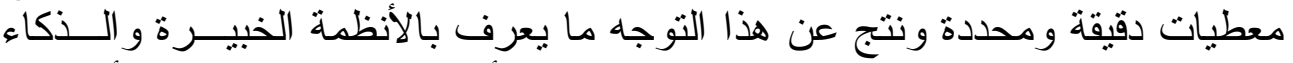

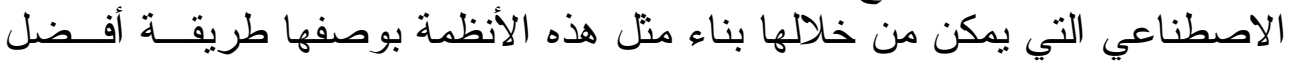
لمعالجة البيانات.

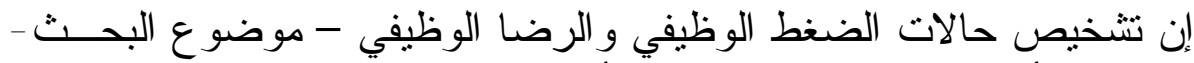

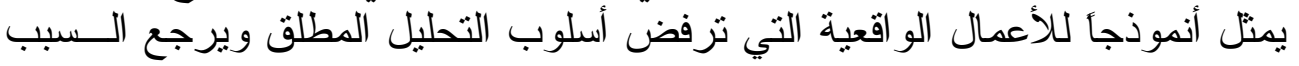

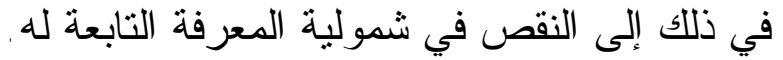

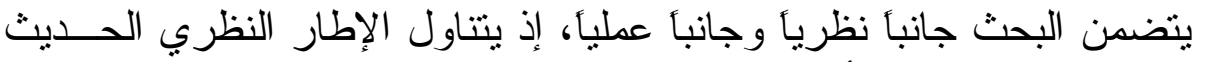

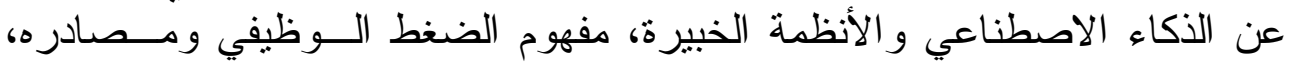

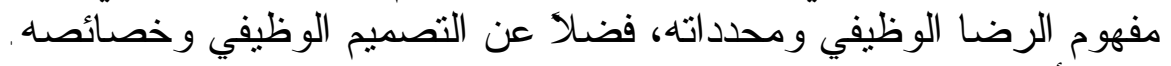

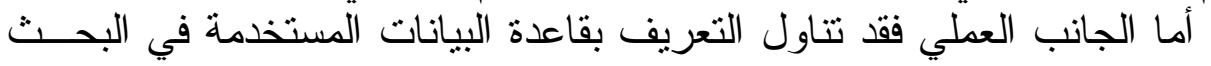

و المصمدة بنظام Access وتعريف و اجهات وبر امجيات النظام المصمدة باستخدام لغة Visual Basic n لغئ

$$
1 \text { - } 1 \text { - الجاتب النظري الاصطناعي }
$$

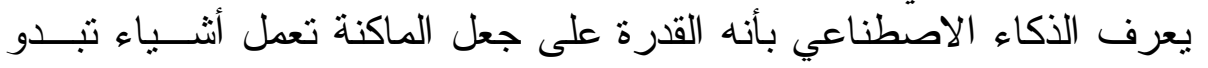

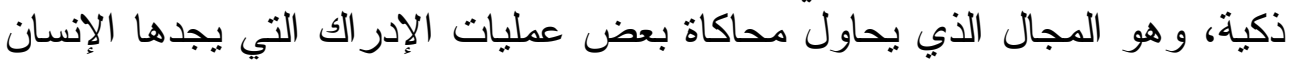

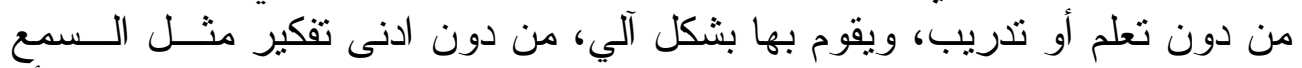

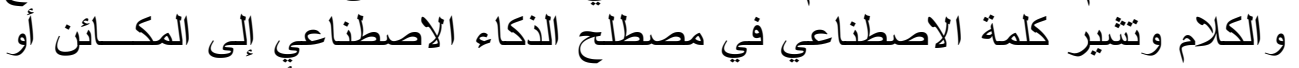

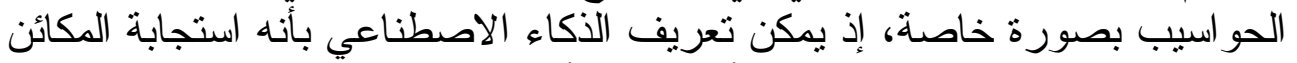

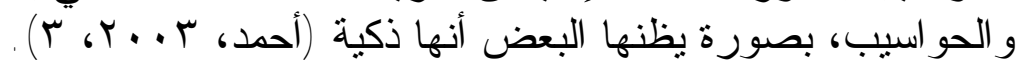

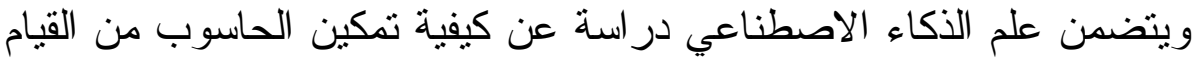

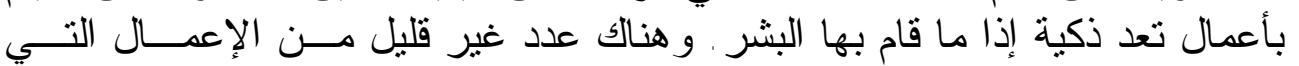

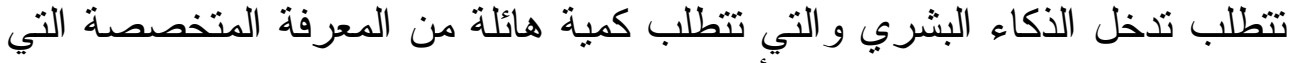
لا يمتلكها معظم الناس، ويقتصر أداءها على على الخبر اء الذين يمتلكون من المعرفة مأ 


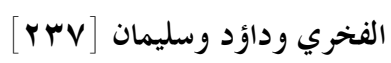

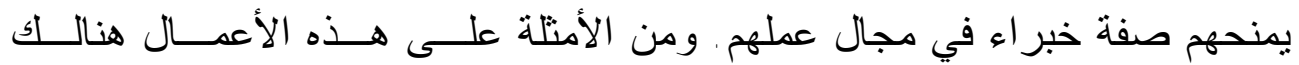
التتخيص الطبي، التصميم الإلكتروني و التحليل العلمي.....وغير ها.

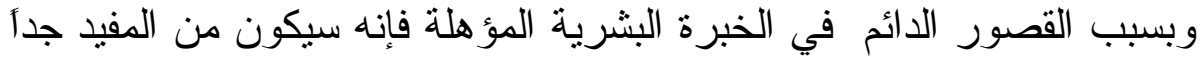

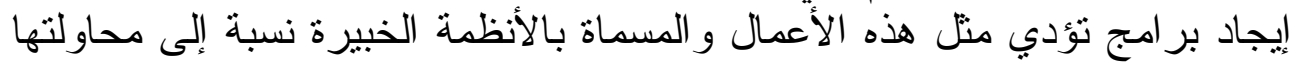

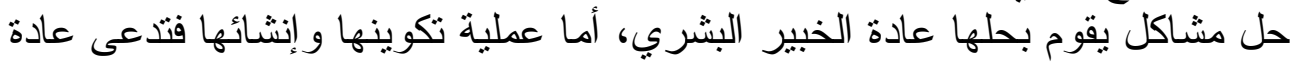
بهندة المعرفة (الأسدي وآخرون،

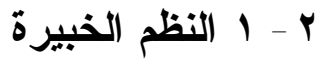 ب ا ب تعريف النظم الخبيرة}

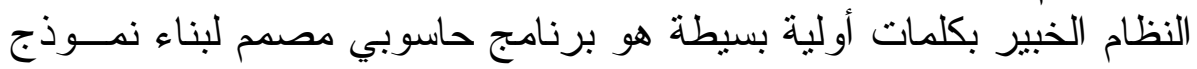

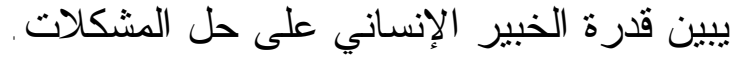

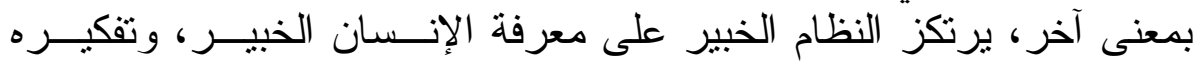

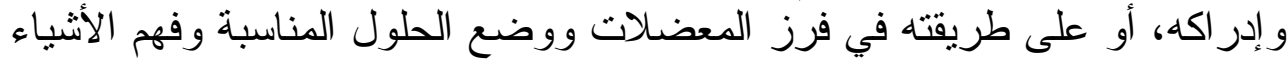

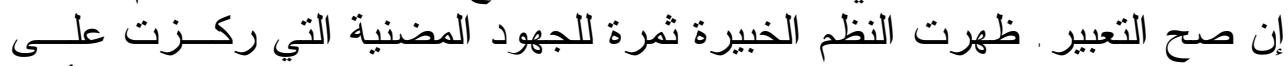
إدارة المجالات التخصصية للمعرفة و البحث عن حلول لمشكلات هذه المعرفة أثناء

نطبيقها.

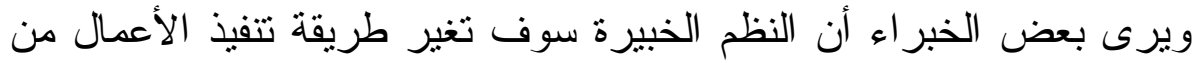

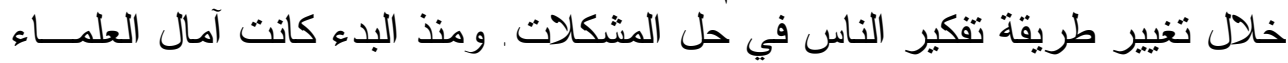

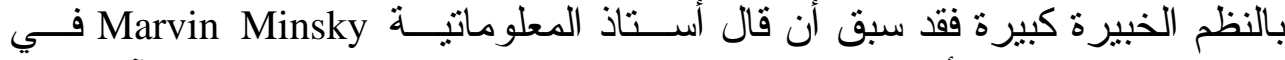

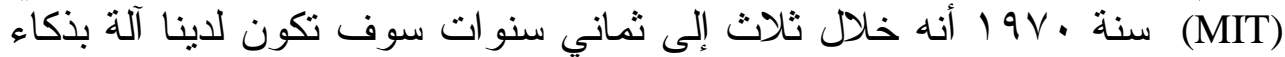

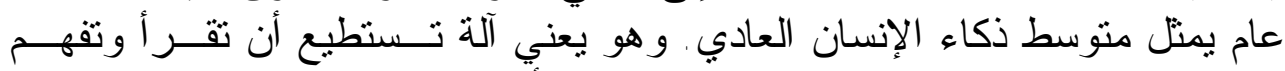

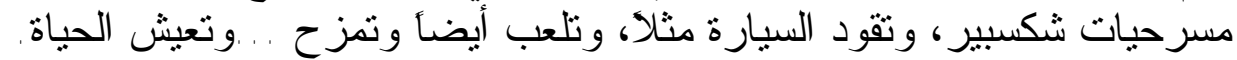

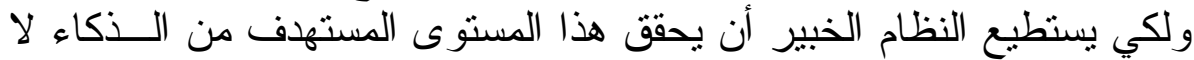

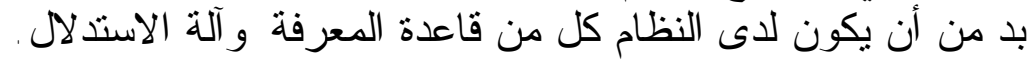

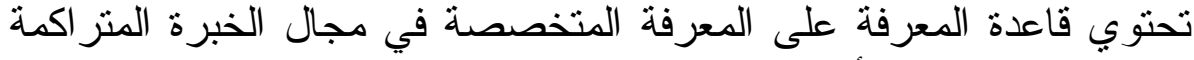

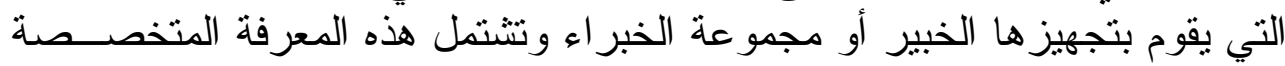
على الحقائق، القو اعد، المفاهيم، و العلاقات التهات.

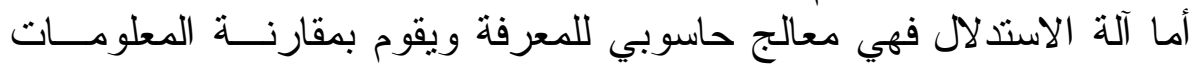

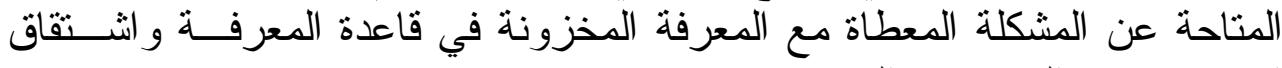
الإستتناجات و التوصيات المفيدة.

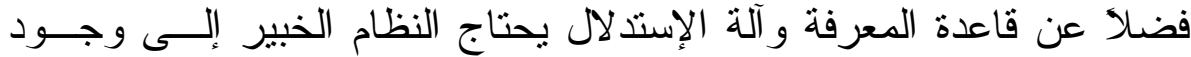

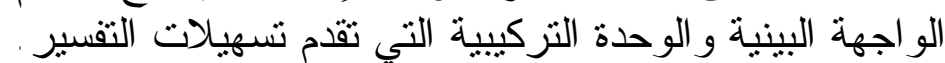

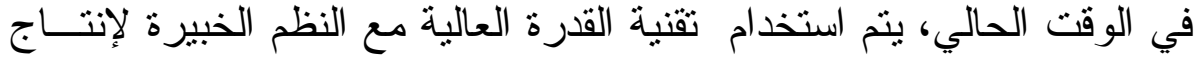

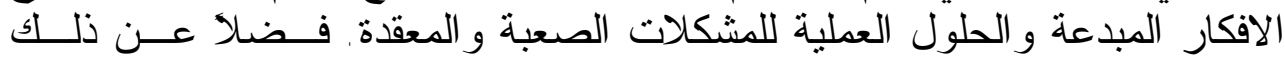

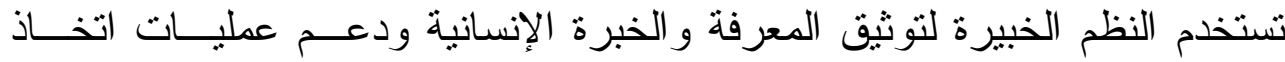




\section{$[r+1]$} حقيبة برجية لاختبار العلاقة بين الضغط الوظيفي والرضا الوظفي...

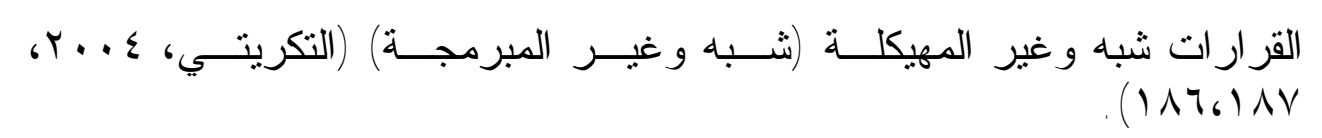

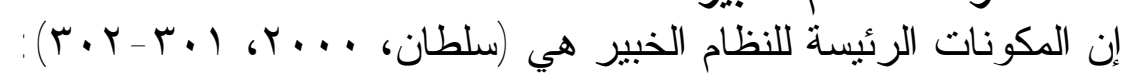

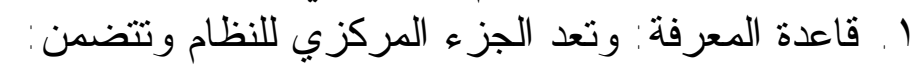

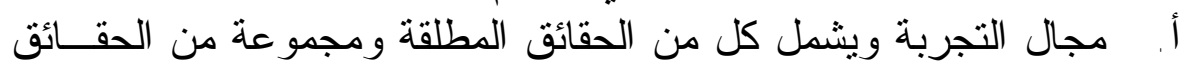

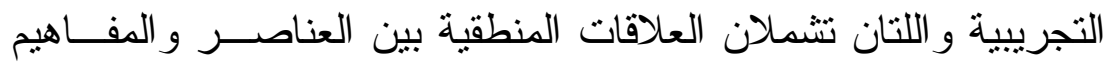

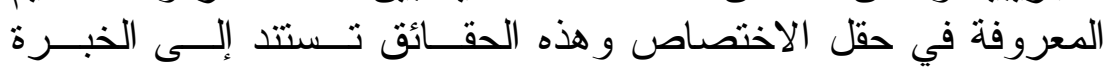

$$
\text { و الممارسة الثنخصية. }
$$

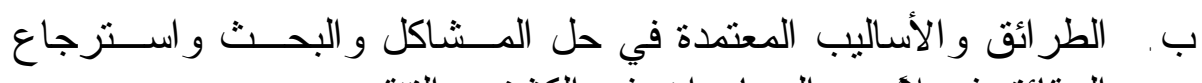
الحقائق فضلا عن المساعدات في الكثف والئ والتنقيب.

ت. تو اعد اللربط بين الأساليب و التي تمثل الحل و والمعارف الأساسية. ا ـ آلة الاستنتاج

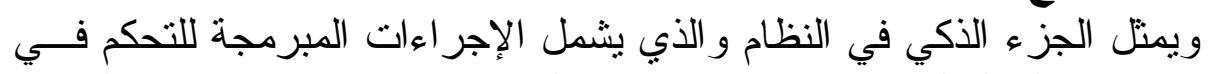

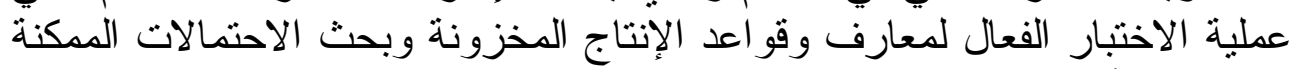

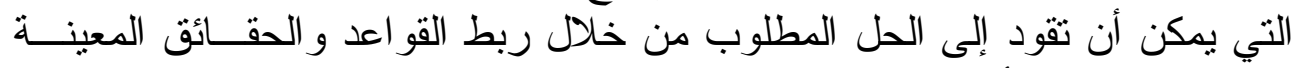

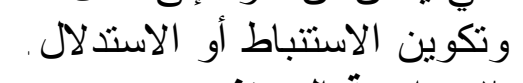
r ا و واجهة المستفيد

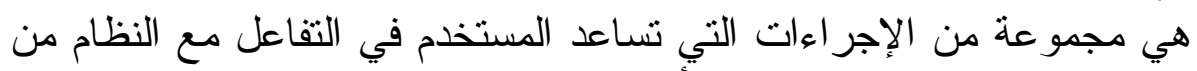

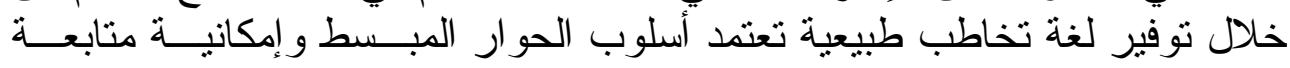

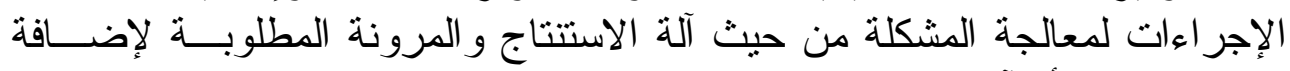
معارف جديدة أو آراء حول التعديلات الحالية.

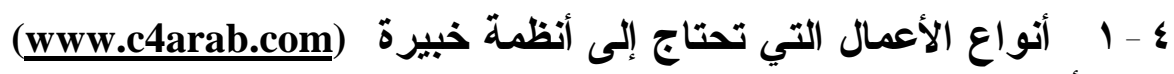

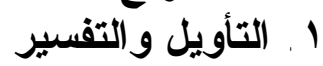
تفسر بمعنى المشاكل التي تحتاج إلى حلها: تشكيل نتائج أو توصيفات رفيعة المستوى من مجمو عة من بيانات معطاة. r r r التنبؤ

تفسر بمعنى المشاكل التي تحتاج إلى حلها: تصور عو اقب محتملـــة نتيجــة

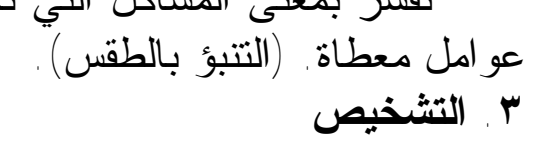

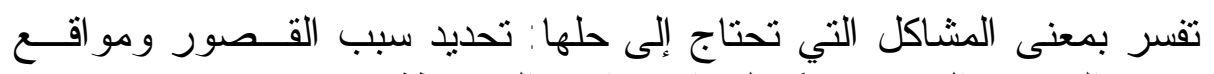
الضعف في الحالات المعقدة بناءً على الاعر اض الع الملاحظة. 
تفسر بمعنى المشاكل التي تحتاج لحلها: إيجاد تشكيل مناسب لمكونات نظــام

ع ـ التصميم

$$
\text { يخدم أهداف منقدمة مع وجود التعديد من القيود . }
$$

0. التخطيط

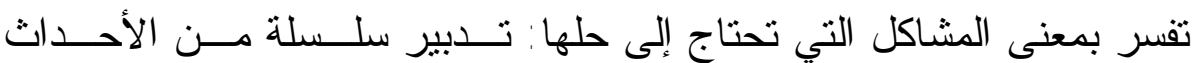

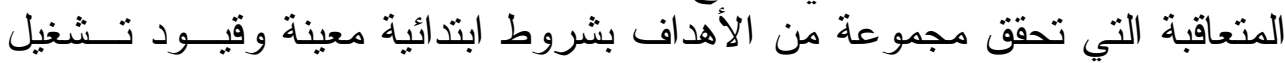
وبما أن الأعمال السالفة الذكر هي آليات مستخدمة في كثير مـــن الأعمـــال زمنية.

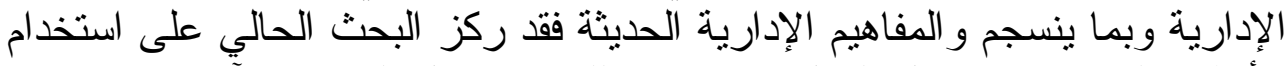

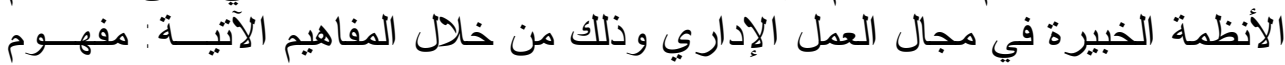

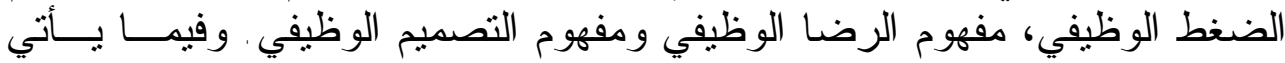

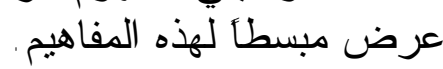

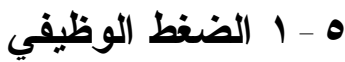

\section{1 -0 - 1 مفهوم الضغط الوظيفي}

يرتبط مفهوم الضغط الوظليفي بالكثير من حقول العلوم الاجتماعية على النحو

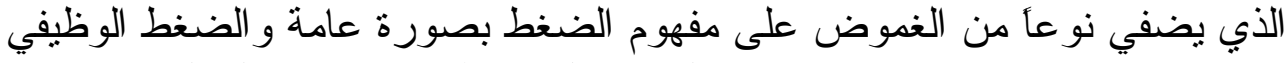

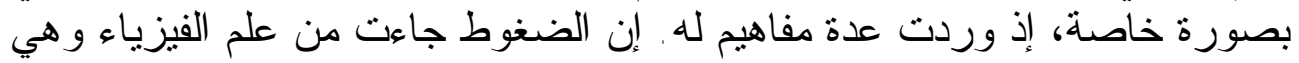

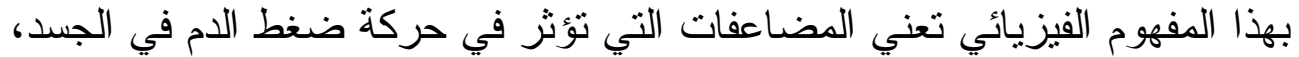

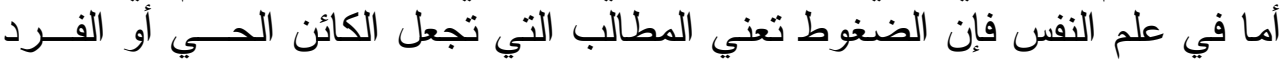

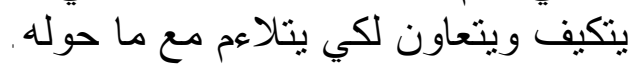

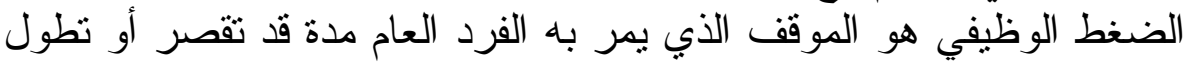

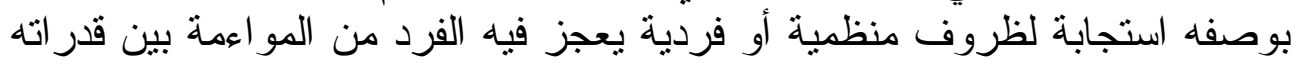

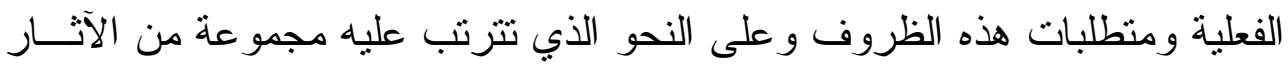

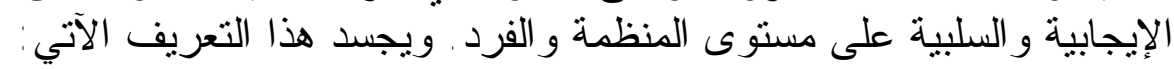

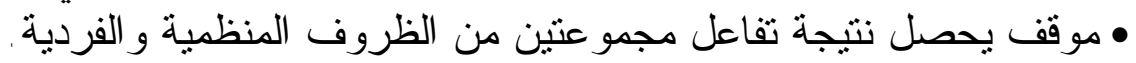

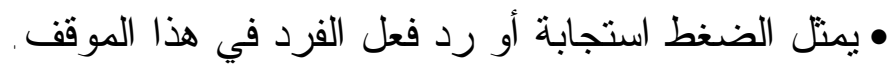

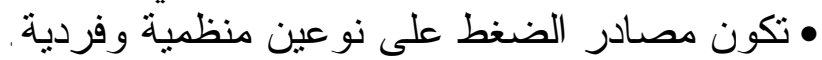

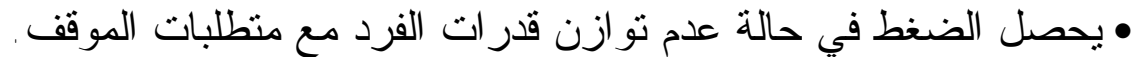

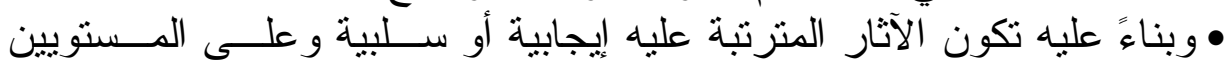

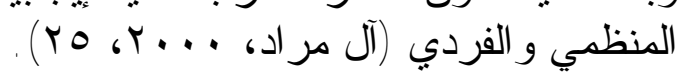

\section{r ـ- - أ مصادر الضغط الوظيفي وأسبابه}

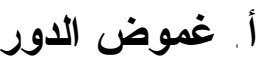

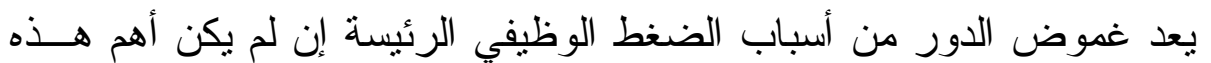

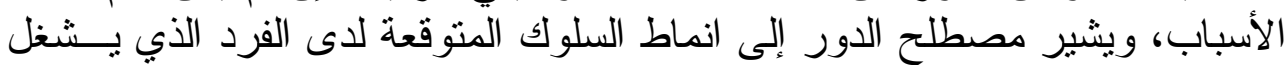




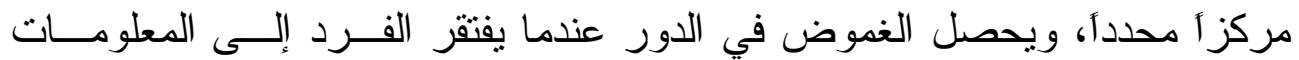

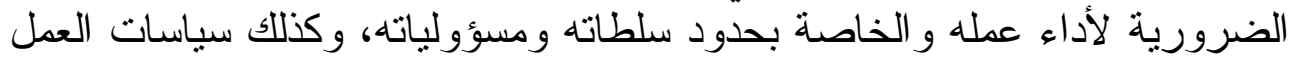

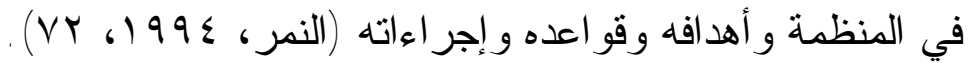

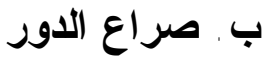

يعد صراع الدور من الأسباب المهمة في ضغط الوظيفة، ويظهر ذلك عندما

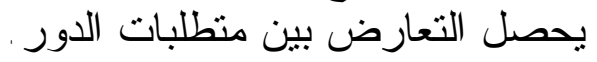
ج. زيادة / انخفاض عبء لألئ الدور الوظيفي

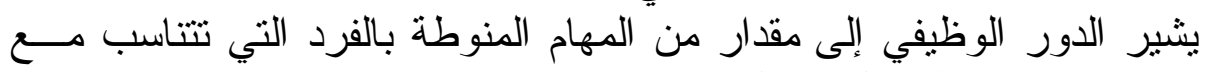
قدر اته ومهار اته في إطار الوقت الإلت المحدد لإنجازه. هـ - الاختلاف المهني

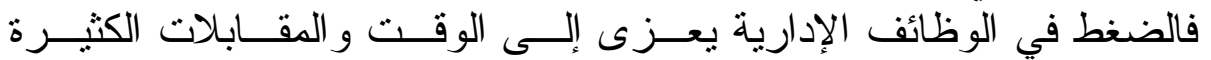
و الصعوبات الخاصة بانجاز معايير الأداء.

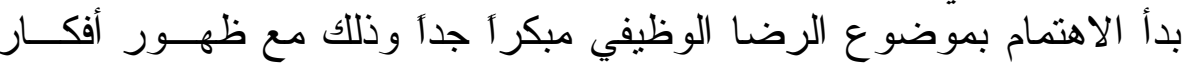

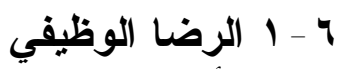

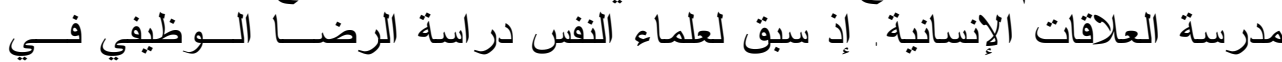

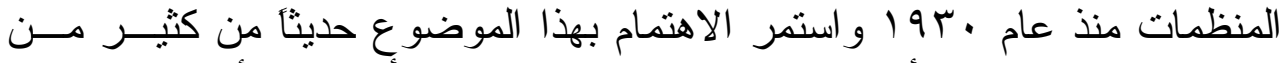

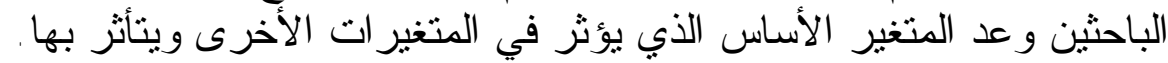

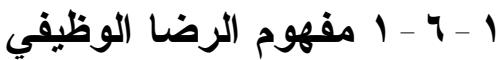

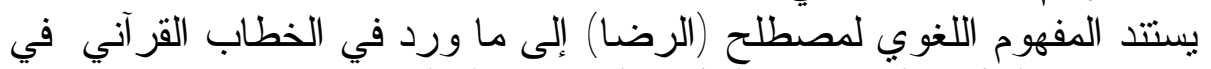

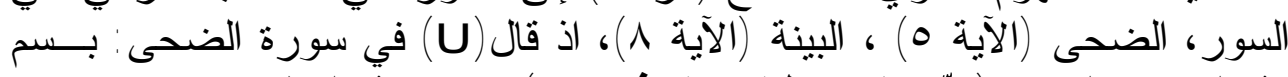

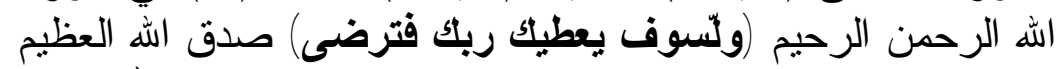

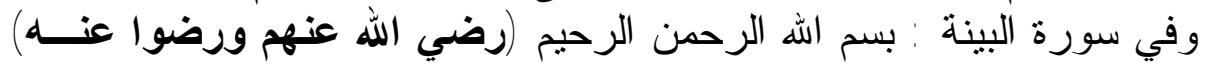

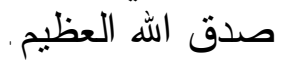

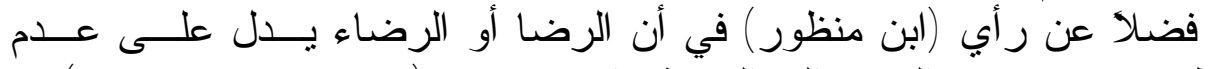

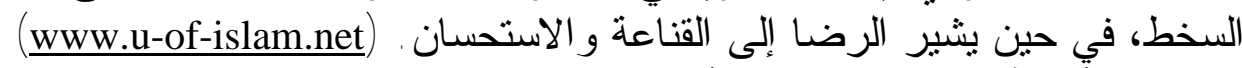

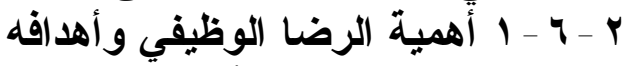

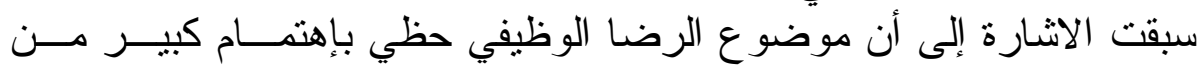

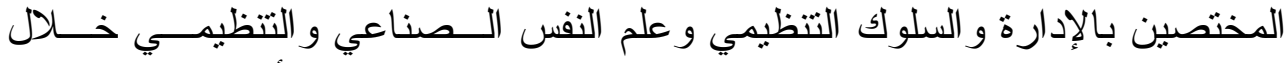

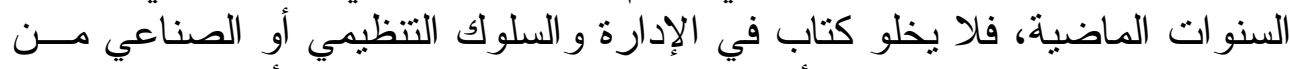

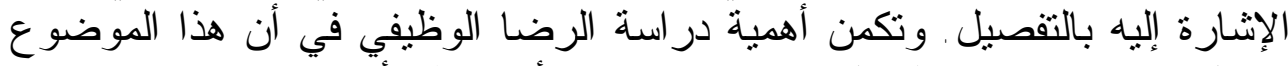

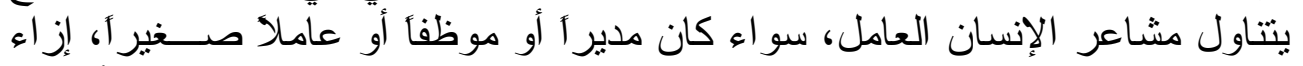

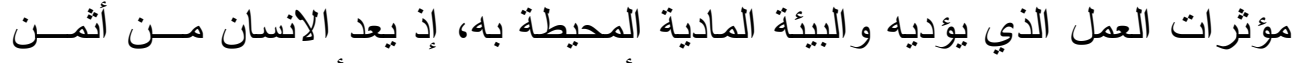

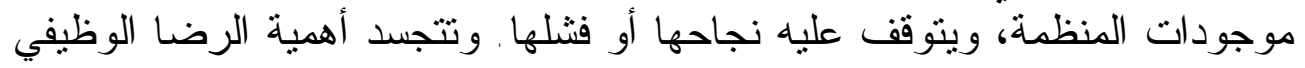

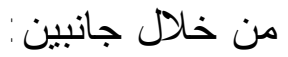


1. الأهية السلوكية والاجتماعية: وهي مجموعة من العوامل التي يحققها الرضا

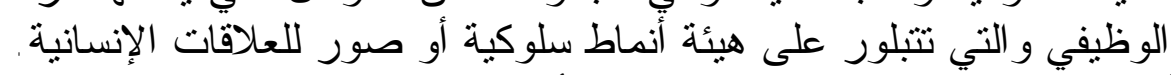

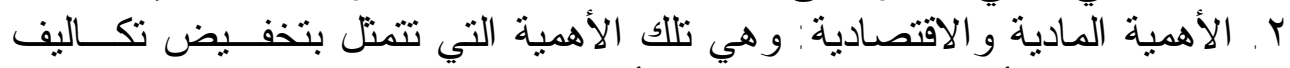

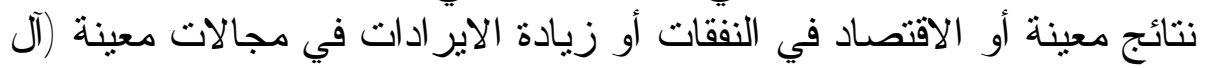

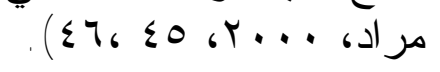

\section{الم - ال - المجوعة الأولىات الرضا الوظيفي الوظيفة}

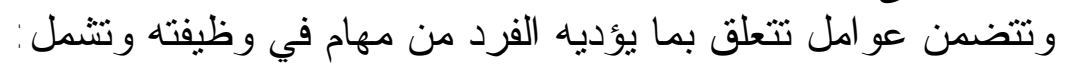

ا ـ الانجاز : وهي اتمام الفرد للمهام الموكلة إليه.

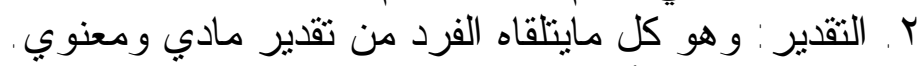

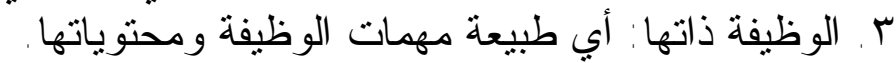

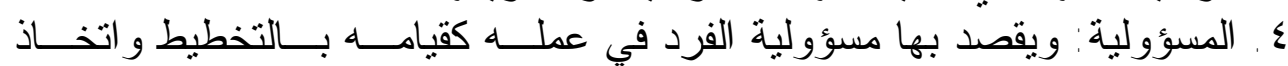

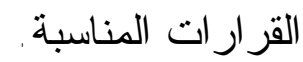

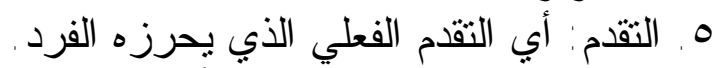

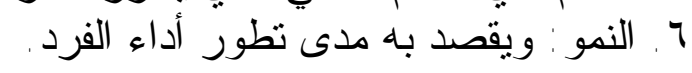

\section{المجموعة الثانية: عوامل بيئة الوظيفة} وهي العو امل التي تحبط بالوظئة الوظيفة وتتحدد من مصادر خارجية.

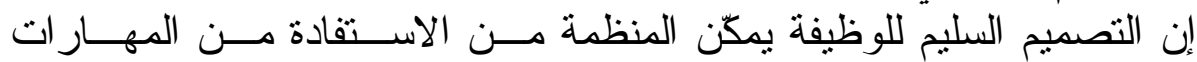

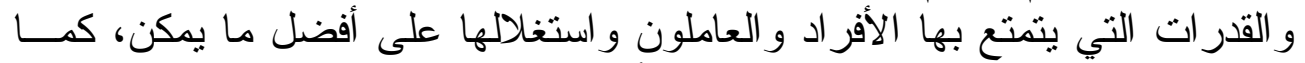

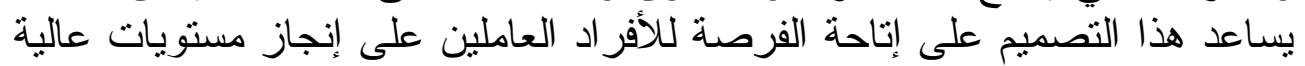

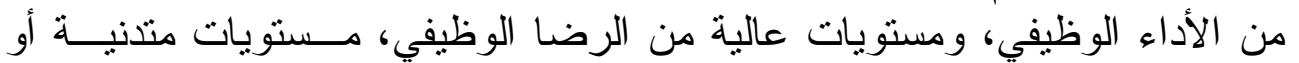

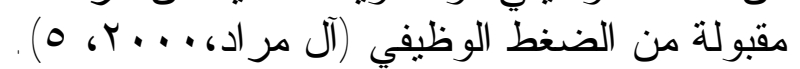

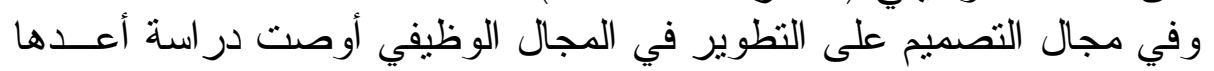

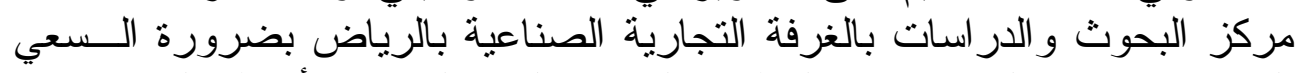

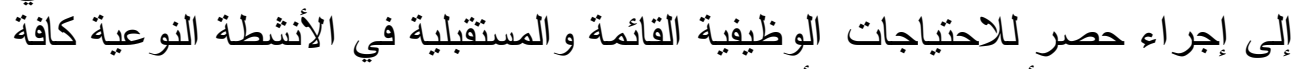

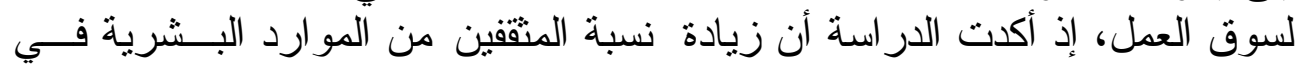

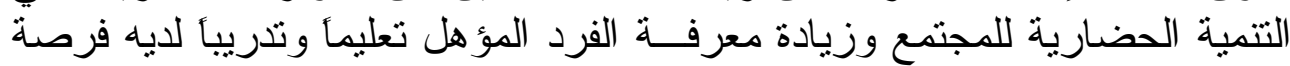

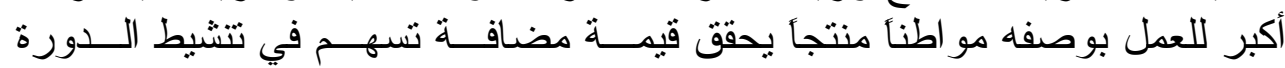

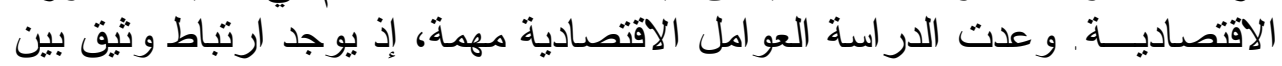

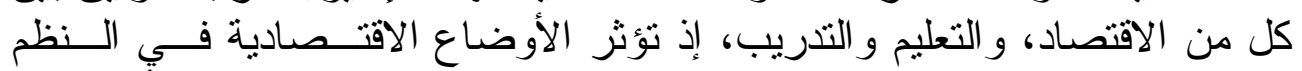

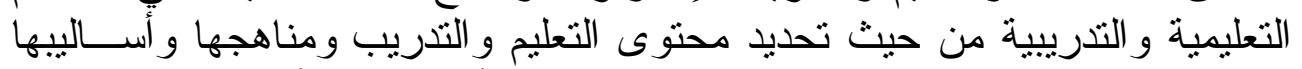

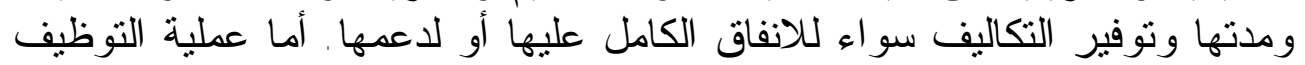


فيتم من خلالها إتاحة فرص العمل للقوى البشرية التي تتم تتميتها وتأهيلها من خلال

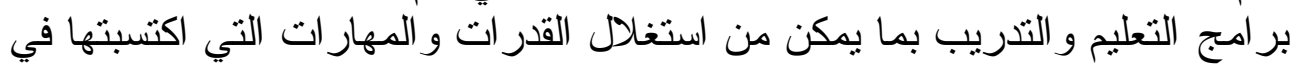

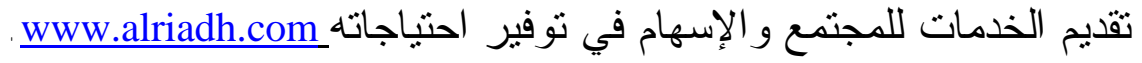

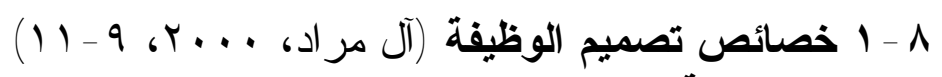

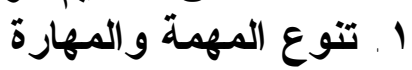

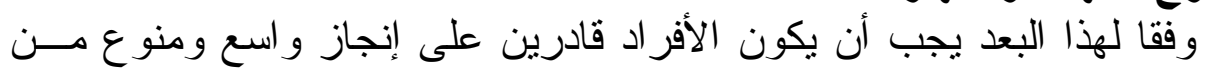

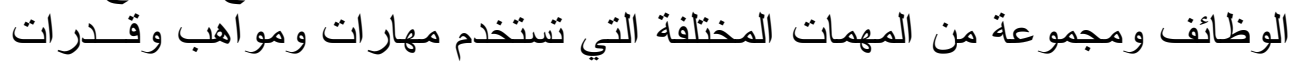

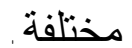

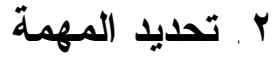

يتجسد هذا البعد من خلال جعل الوظيفة أكثر تز ابطأ وتكاملا فـي مهامهــا ل التشكل وحدة عمل متكاملة. r. أهمية المهمة

يقصد بهذا البعد امتلاك خاصية التأثثر في الآخرين و أن يكون هــــا التـأثير

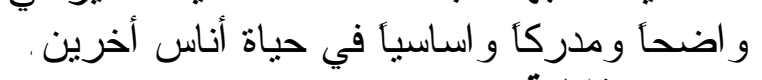

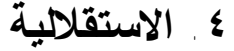

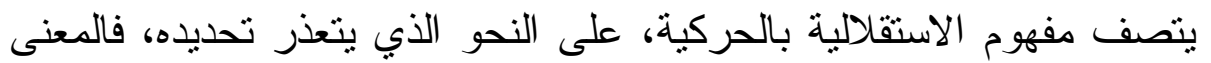

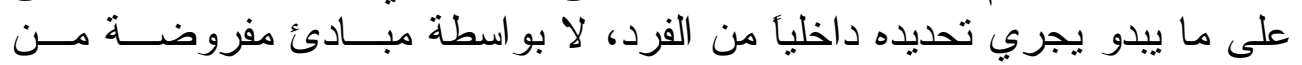

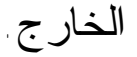

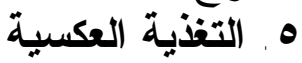

يقرر هذا المبدأ ضرورة ومنافع توفير معلومات التغذية العكسية عـنـ أداء الأفراد العاملين الذين ينجزون المهمات.

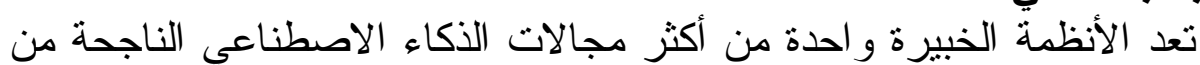

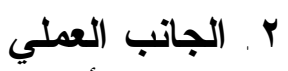

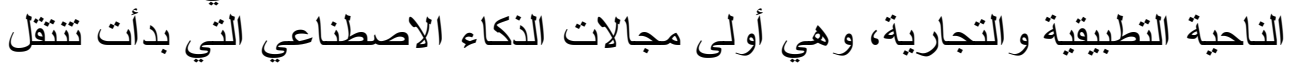

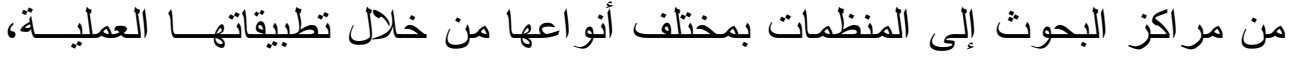
الأمر الذي أدى إلى زيادة أهية هذا النو النوع من الأنظمة.

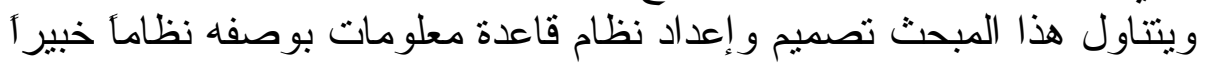

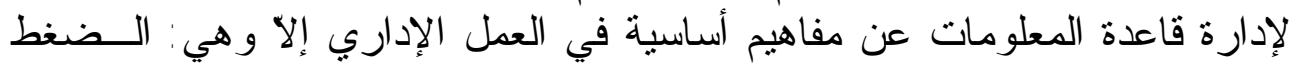
الوظيفي، والرضا الوظيفي، و التصميم الوظيفي.

(النظام المقترح r- r-

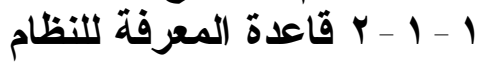

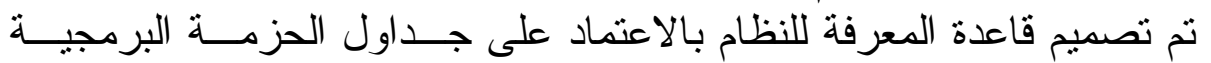

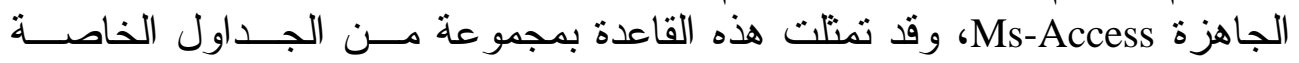




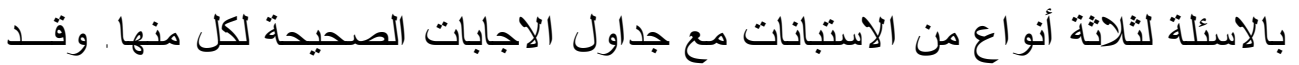

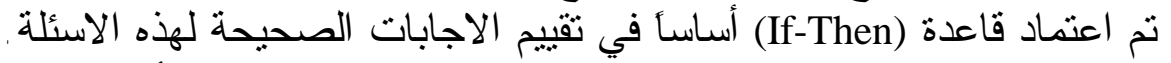

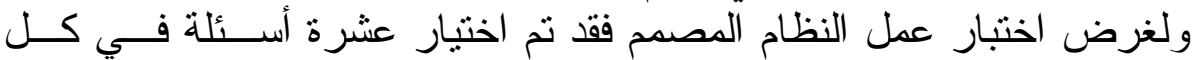

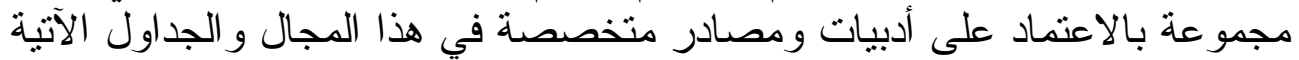

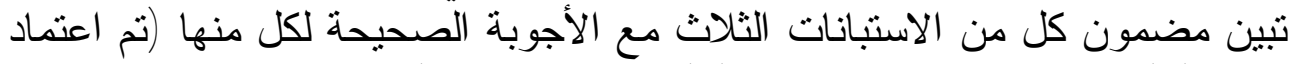
الرقم ( ) للاجابة الصحيحة و الرقم ( • ) للاجابة الخاطئة) .

\begin{tabular}{|c|c|c|}
\hline & يبين مجموعة الاسئلة المستخدمة لقياس الضغط الوظيفي & \\
\hline الاجابة & الاسئلة: & ت \\
\hline & أحس بالاجهاد بعد إكمالي عمل مهم & 1 \\
\hline & لدي القدرة على أن أكون هادئة بعد انجاز عمل يخلق التوتر & r \\
\hline & أعيد العمل مرة ثانية من البداية عند الضرورة دون ان اصاب بالاحباط & $\mathrm{r}$ \\
\hline & أتعب بسر عة اذا كان المر اجع سريع الانفعال & $\varepsilon$ \\
\hline & لا اتمكن من استغلال كامل قدر اتي على نحو سليم & o \\
\hline & لايسمح وقت العمل المخصص لي باداء كل ما هو متوقع مني & 7 \\
\hline & أثشعر بأن فرص التدريب المتاحة لي غير كافية لاداء و اجباتي على نحو سليم & $\bar{V}$ \\
\hline & اتقبل مقاطعة الاخرين دون رد فعل سلبي & $\Lambda$ \\
\hline & اشتعر بأنني انجز المهام في ظل سياسات وتوجيهات متعارضة & 9 \\
\hline & 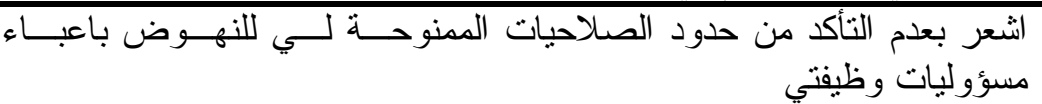 & 1 . \\
\hline
\end{tabular}

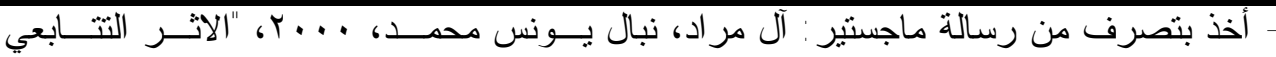

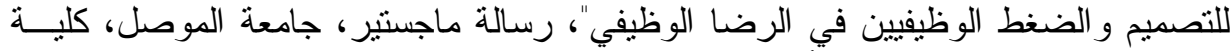
الإدارة والاقتصاد قشم إدارة الأعمال.

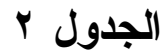

مجموعة الاجابات الصحيحة المفترضة عن اسئلة الضفط الوظيفي

\begin{tabular}{|c|c|}
\hline الاجابة الصحيحة المفترضة & التسلسل \\
\hline 1 & 1 \\
\hline . & r \\
\hline - & $r$ \\
\hline 1 & $\varepsilon$ \\
\hline$T$ & 0 \\
\hline$T$ & 7 \\
\hline$T$ & $\mathrm{v}$ \\
\hline$\cdot$ & $\Lambda$ \\
\hline$T$ & 9 \\
\hline$T$ & 1. \\
\hline
\end{tabular}




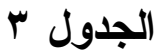

مجموعة الاسئلة المستخدمة لقياس الرضا الوظيفي

\begin{tabular}{|c|c|c|}
\hline الاجابة & الاسئلة & $ت$ \\
\hline & الشعر بقلة الفرص المتاحة لي للتقام في وظيفتي الحالية & 1 \\
\hline & اثشعر بقلة الفرص المتاحة لي في تعلم مهار ات جديدة في وظيفتي & r \\
\hline & اثشعر بعدم الرضا تجاه معاملة رئيسي المباثر لي & r \\
\hline & لاتعتمد الادارة اسلوب المشاركة في صنع القرار ات & $\varepsilon$ \\
\hline & يمنحني عملي شعور بالثقة بالنفس & 0 \\
\hline & يسبود النقير و الاحتر ام الثخصي و الذاتي بين الافر اد & 7 \\
\hline & افتخر واعتز لانتمائي لهذه المؤسسة & $\mathrm{v}$ \\
\hline & احس ان زملائي في العمل هم افر اد عائلتي & $\Lambda$ \\
\hline & لايمنحني نجاحي في العمل احساسا برقي مكانتي & 9 \\
\hline & لاتقدم لي وظيفتي فرصة للاستقر ار الوظيفي & 1. \\
\hline
\end{tabular}

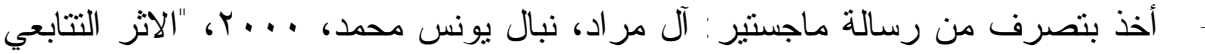

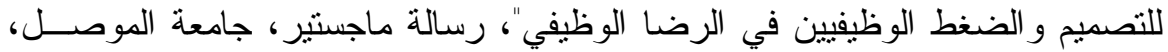
كلية الإدارة و الاقتصاد ققسم إدارة الأعمال.

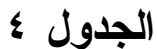

مجموعة الاجابات الصحيحة المفترضة عن اسئلة الرضا الوظيفي

\begin{tabular}{|c|c|}
\hline الاجابة الصحيحة المفترضة & $ت$ \\
\hline$\cdot$ & $T$ \\
\hline 1 & r \\
\hline 1 & r \\
\hline 1 & $\varepsilon$ \\
\hline 1 & 0 \\
\hline 1 & 7 \\
\hline 1 & $\mathrm{~V}$ \\
\hline$T$ & $\Lambda$ \\
\hline - & 9 \\
\hline . & 1. \\
\hline
\end{tabular}




\section{- الجدول}

مجموعة الاسئلة المستخدمة لقياس التصميم الوظيفي

\begin{tabular}{|c|c|c|}
\hline الاجابة & الاسئلة & ت \\
\hline & انجز فعاليات مختلفة تتطلب مني تتوع في المهار ات الوظيفية & 1 \\
\hline & اطتيح لي وظيفتي فرصئ اضلئية افية لانجاز مهام اخرى تقع خارج & r \\
\hline & احس بأن وظيفتي هي موضع تقدير من الاخرين & $r$ \\
\hline & تتكامل نتائج عملي على نحو منسلسل من البداية إلى النهاية & $\varepsilon$ \\
\hline & اتحمل مسؤولية انجاز العمل منذ بدايته وحنى نهايته & 0 \\
\hline & امتلاك القدرة على انجاز العمل بصورة مستقلة عن الاخرين & 7 \\
\hline & تسمح الوظيفة لي باتخاذ عدد من القر ار ات بنفسي & $\mathrm{v}$ \\
\hline & استخدم المبادرة الثخصية أو اتخذ ما ارى مناسبا في العمل & $\wedge$ \\
\hline & اعمل معهر على مستوى جودة ادائي للعمل بو اسطة زملائي الذين & 9 \\
\hline & طبيعة عملي تزودني بالمعرفة الكافية عن نتائج انجازي له & $1 \cdot$ \\
\hline & والافتصن من رساد الوظيفيير & \\
\hline
\end{tabular}

\section{7}

مجموعة الاجابات الصحيحة المفترضة عن اسئلة التصميم الوظيفي

\begin{tabular}{|c|c|}
\hline الاجابة الصحيحة المفترضة| & \multicolumn{1}{|c|}{} \\
\hline$\cdot$ & $r$ \\
\hline 1 & $r$ \\
\hline 1 & $\varepsilon$ \\
\hline 1 & 0 \\
\hline 1 & $r$ \\
\hline 1 & $v$ \\
\hline$\cdot$ & $\wedge$ \\
\hline$\cdot$ & 9 \\
\hline 1 & 1 \\
\hline 1 &
\end{tabular}


r و - r و و اجهات وبرامجيات النظام (آلة الاستدلال)

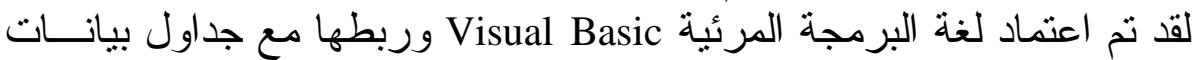

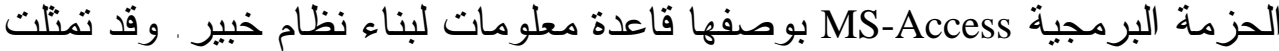

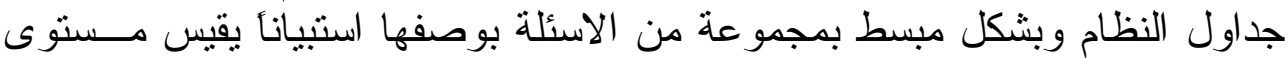

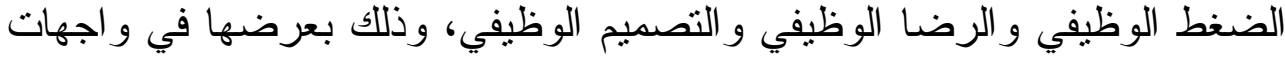

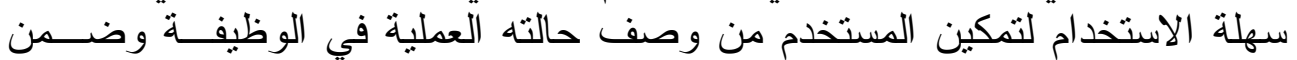

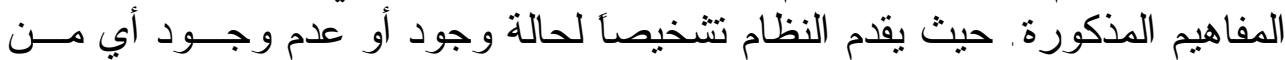

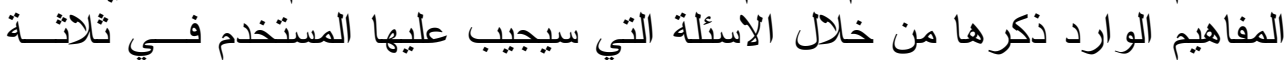

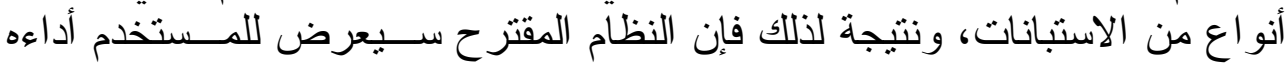

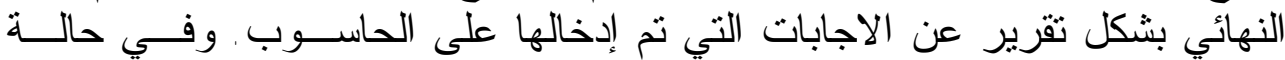

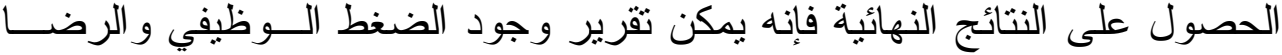

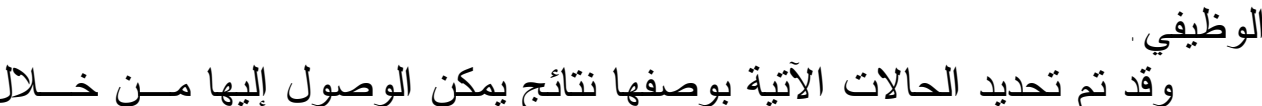

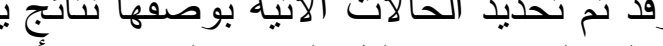
عمل النظام المصمم وتحليل التقرير النهائي بالأداء:

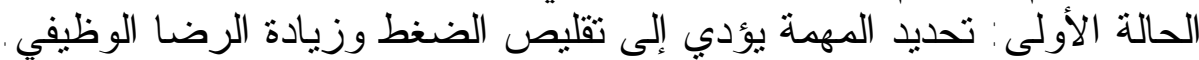

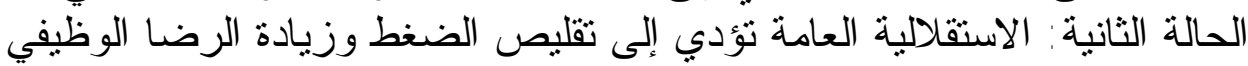

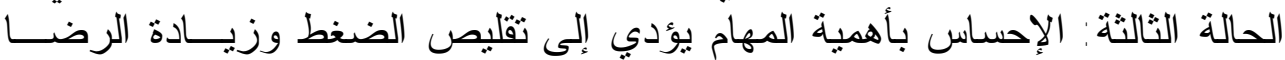

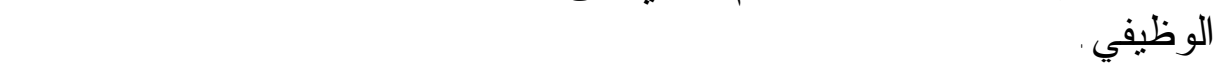

الحالة الر ابعة : تتوع المهمة، تتوع المهارة، تحديد المهمة، الاســتقلالية و التغذيــة

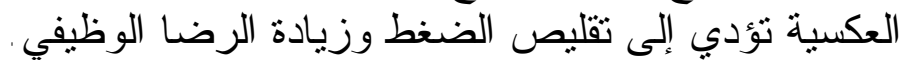

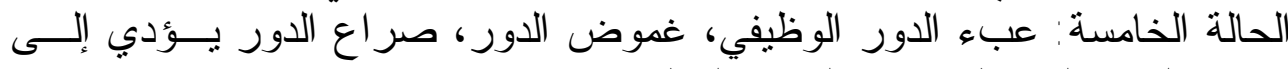
تقليص الضغط وزيادة الرضاء الوظئ الوظيفي.

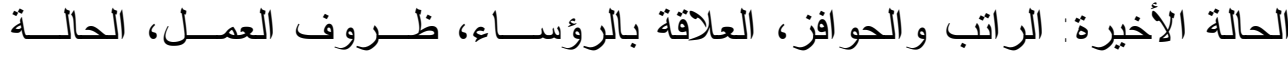

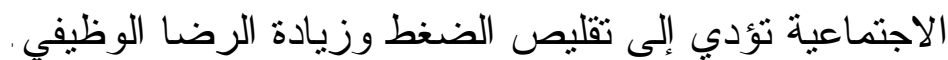

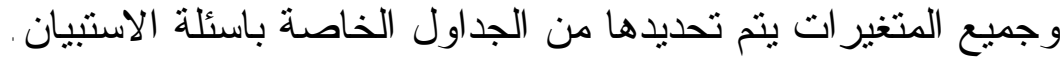

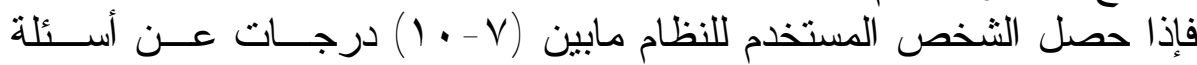

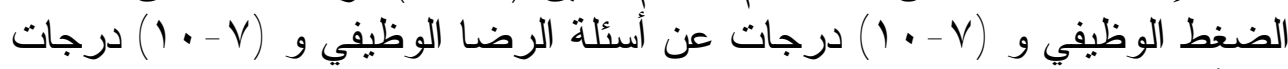

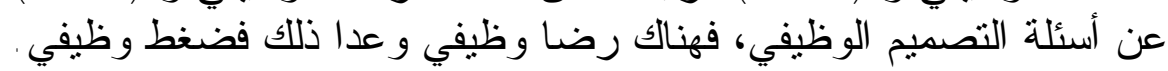




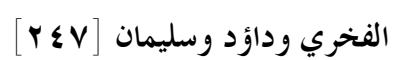

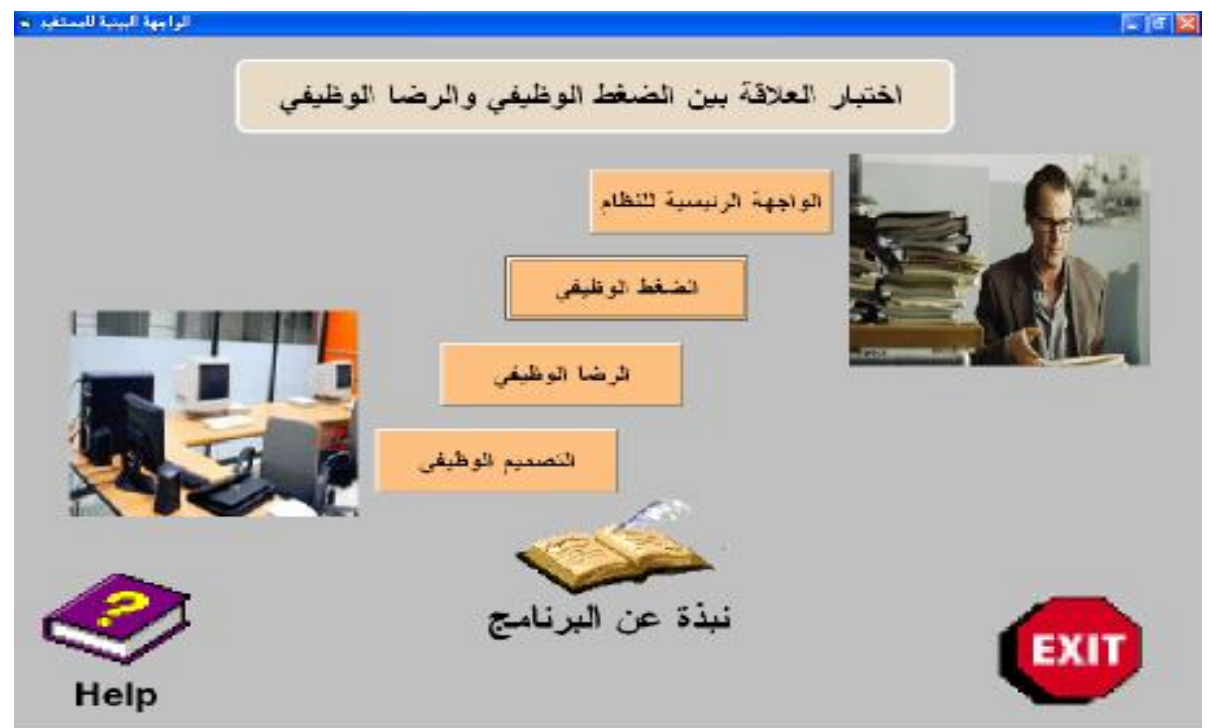

\section{الشكل}

الواجهة الرئيسة للنظام

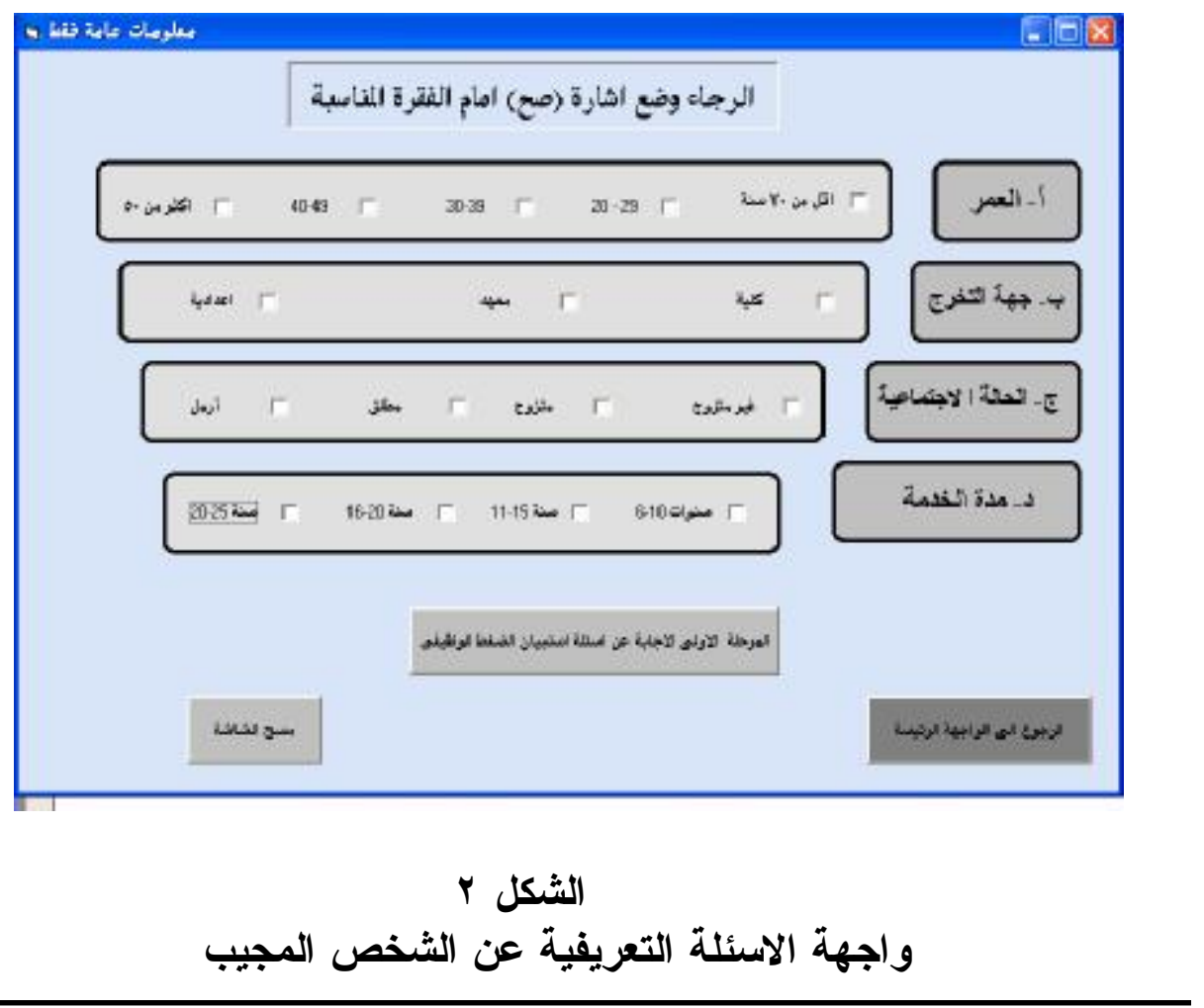


[ $r \leqslant \wedge]$ حقيبة برجية لاختبار العلاقة بين الضغط الوظيفي والرضا الوظيفي...

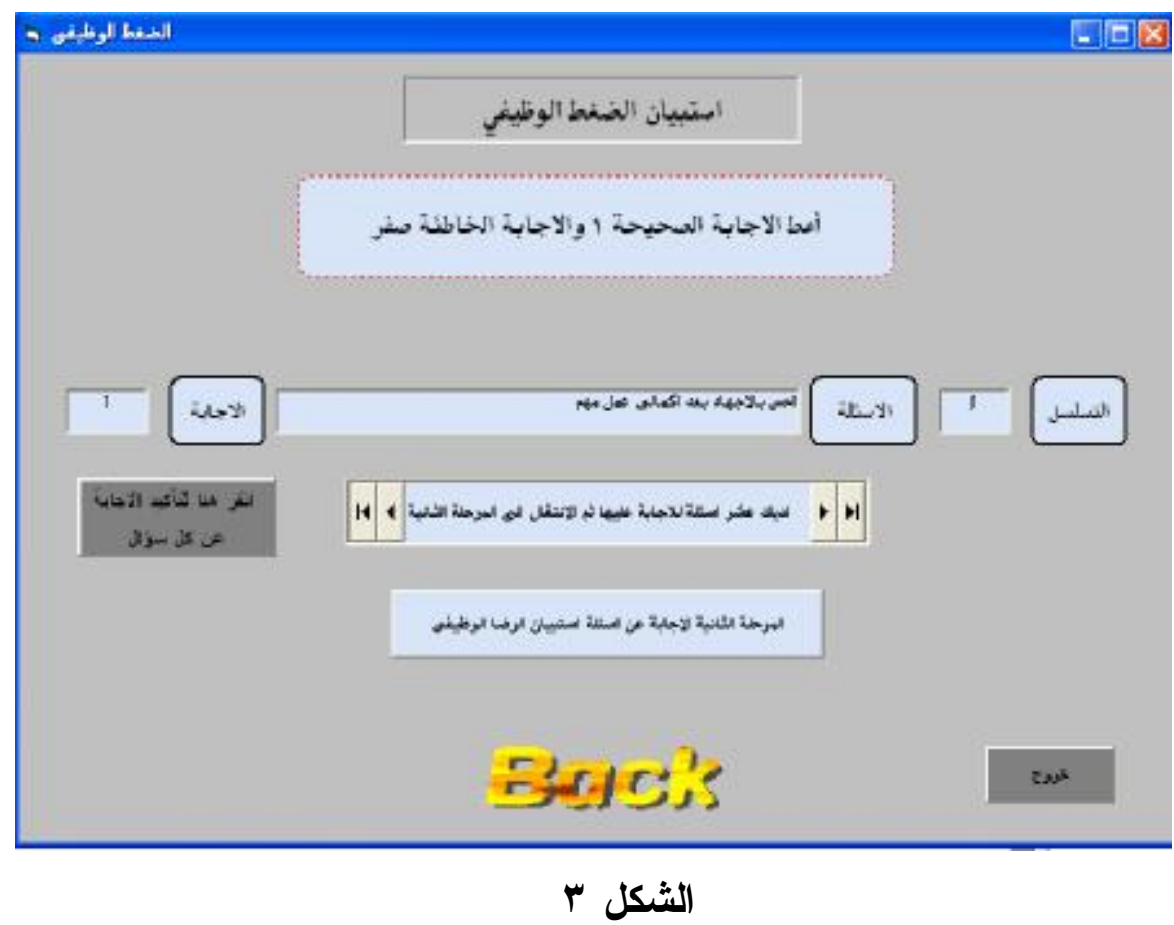

واجهة اسئلة استبيان الضغط الوظيفي

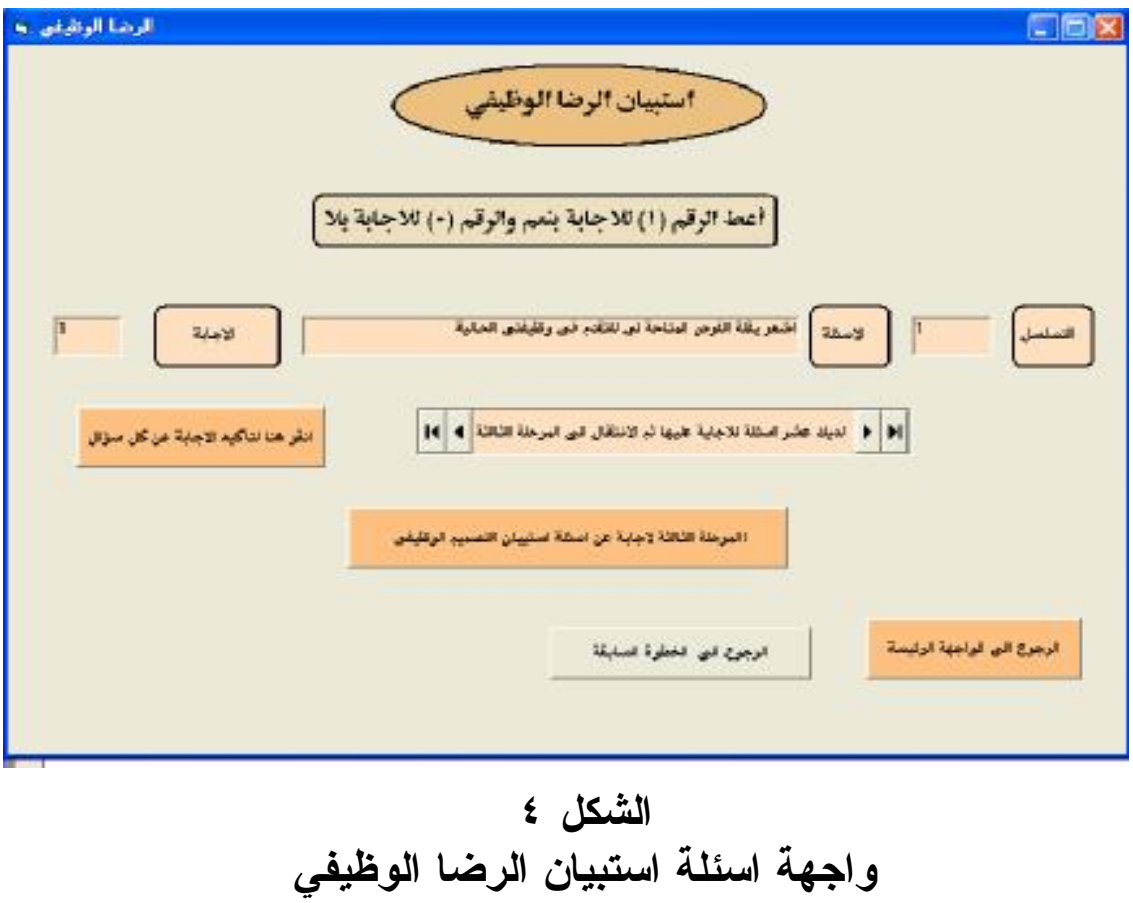




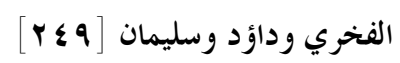

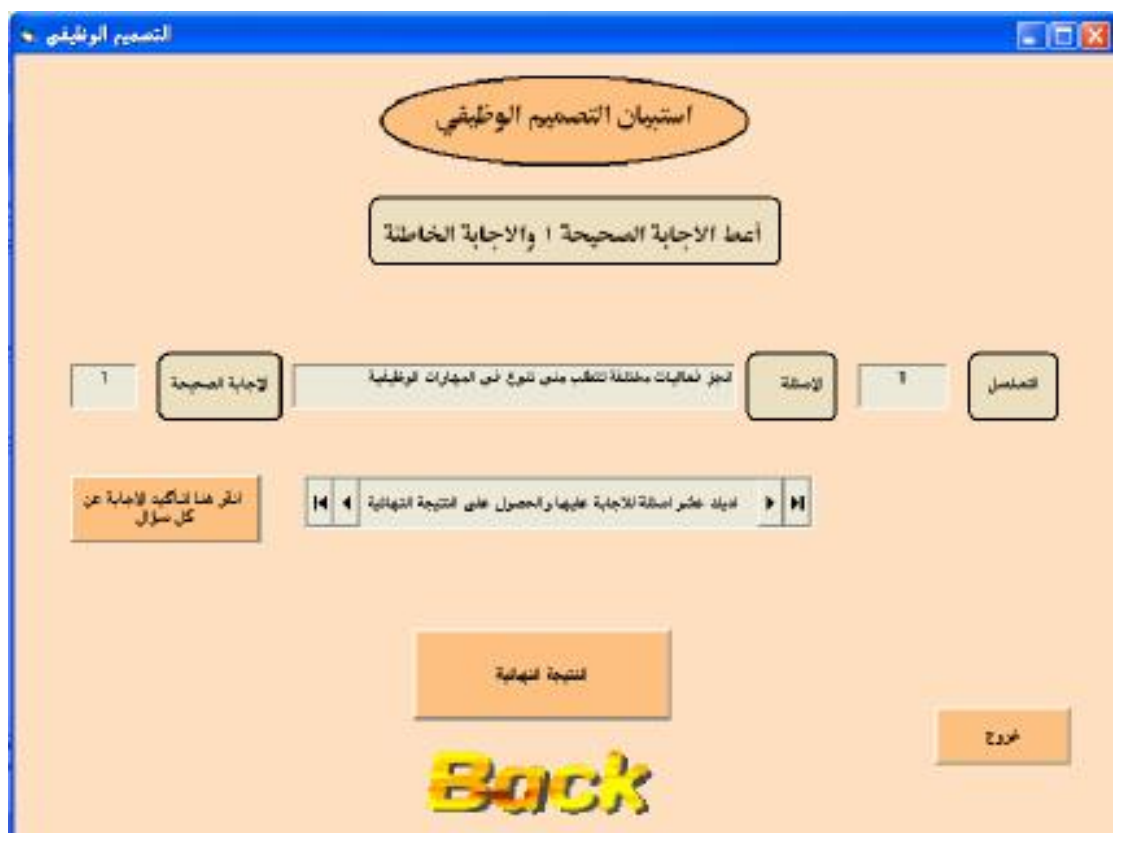

- الثكل

واجهة اسئلة استبيان التصميم الوظيفي

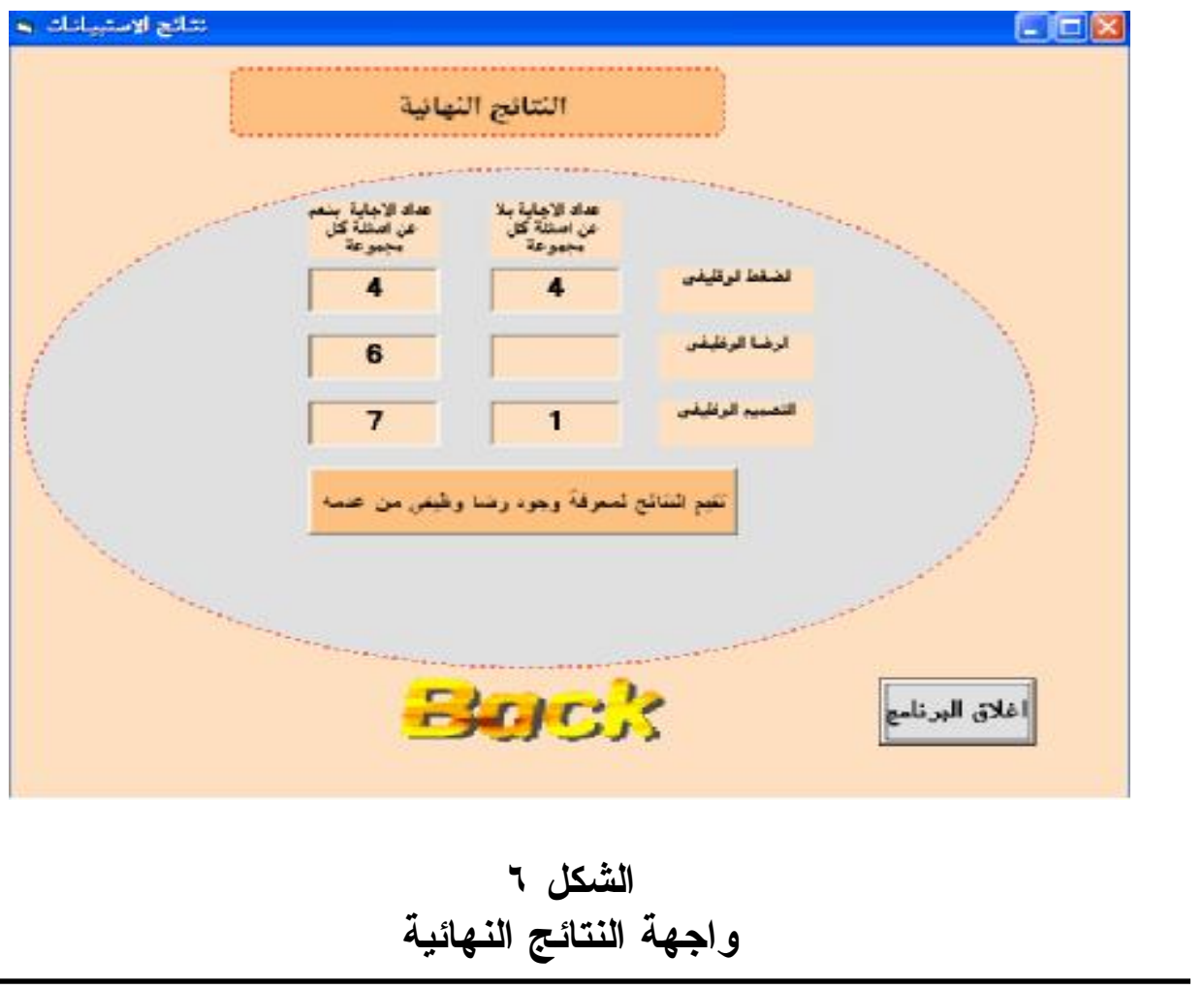




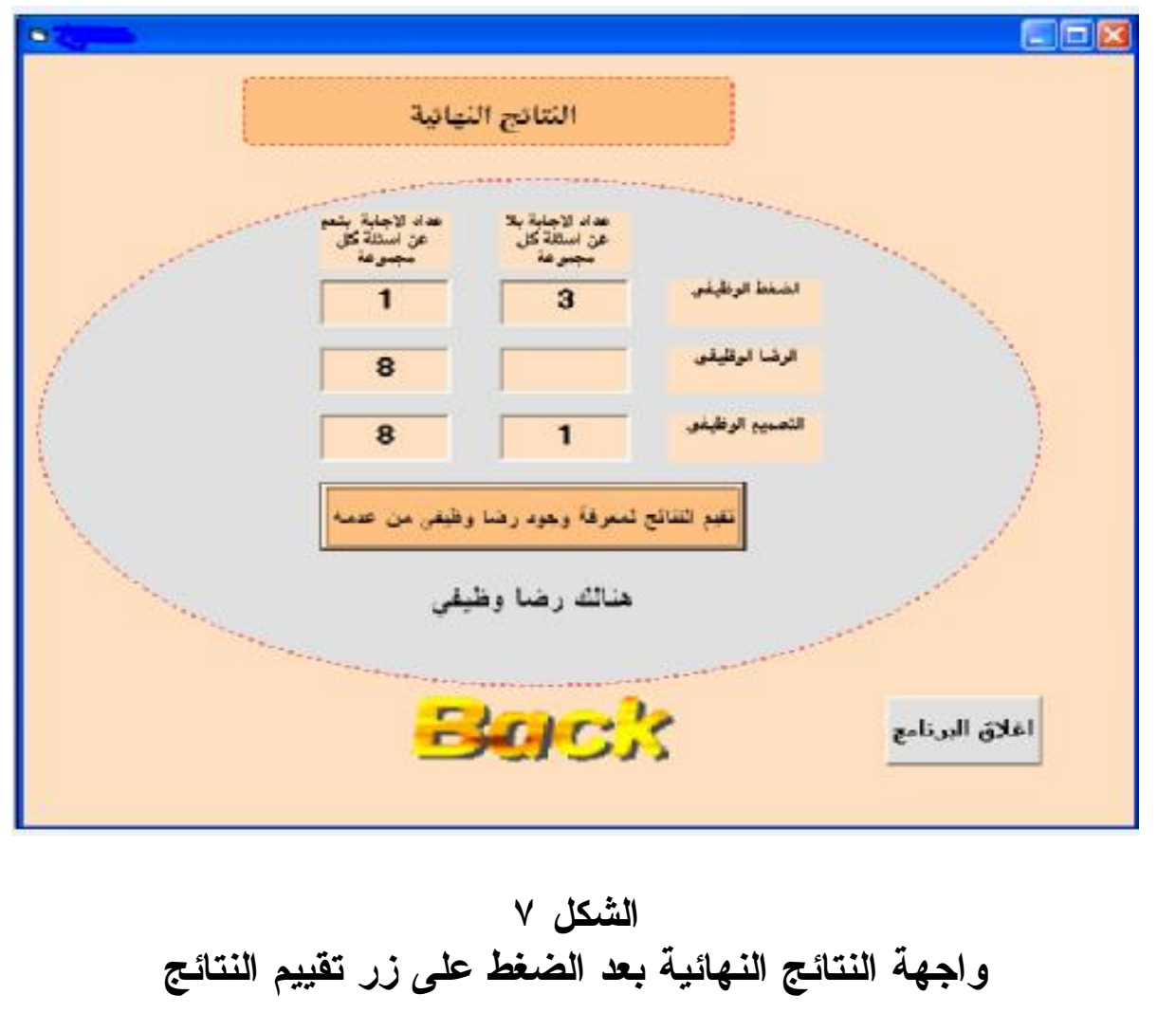

الاستتنتاجات

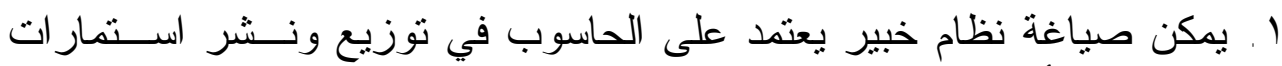

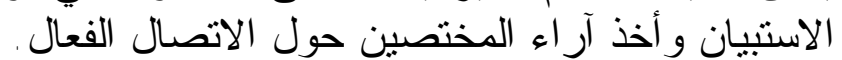

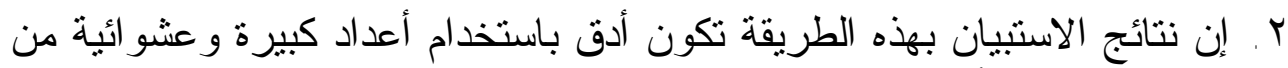

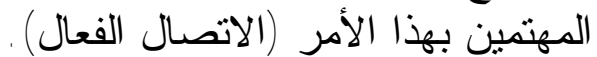

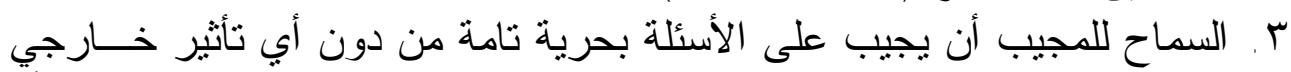

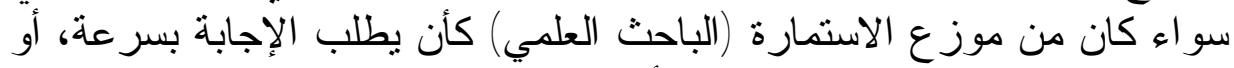

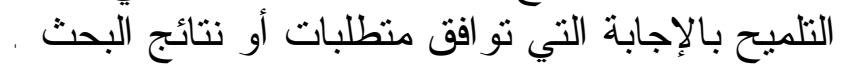

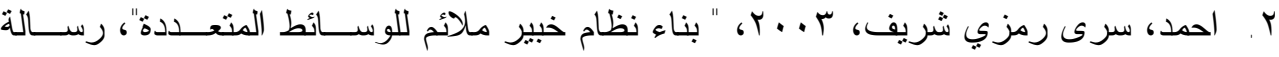

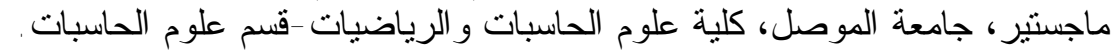

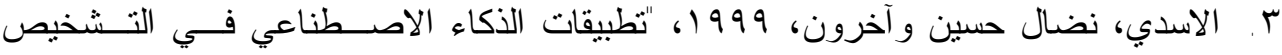
الطبي"، مجلة تتمية الر افدين، العدد الخرن، ه، المجلد آب، العر اق - الموصل. 


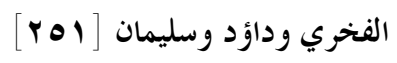

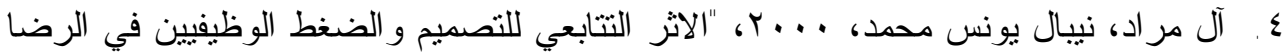

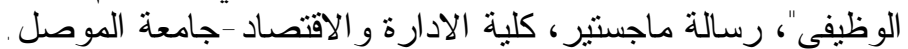

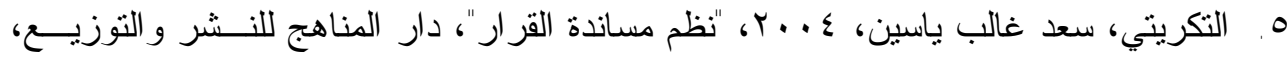

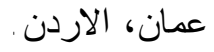

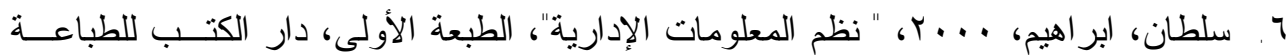

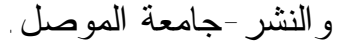

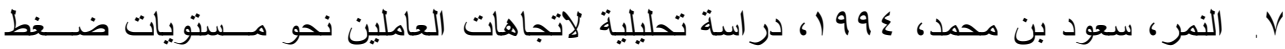

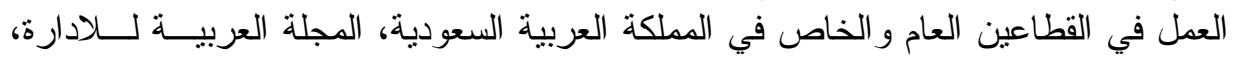

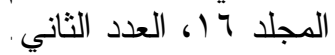
www. C4arab.com .A عن www.u-of-islam.net .9 • ا . ابن منظور، "لسان العرب المحيط"، المجلد الخامس .

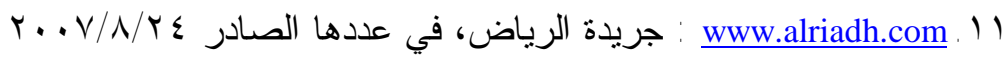

